\title{
Re-Volution Sampler - The Aesthetics of a Participatory Archive of Political Songs
}

\author{
Daniel Cermak-Sassenrath \\ IT University \\ Copenhagen, DK \\ dace@itu.dk
}

\author{
Stina Hasse \\ IT University \\ Copenhagen, DK \\ shaj@itu.dk
}

\begin{abstract}
This article describes and reflects upon the Re-Volution Sampler installation; an exploratory work to investigate how sonic archival material can be disseminated in engaging ways. The Re-Volution Sampler is a participatory installation which consist of a multi-layered assemblage of sonic documents. Ten political songs represent a multi-lingual mix of international, European and local Danish titles from the last decades. Participants can listen to songs and sing along, applaud, cheer or add verbal comments; they can also start new recordings. During an evaluation period of one week at a semi-public location, qualitative and quantitative methods are employed to collect data on the installation's engaging properties. We observe lively, shared and constructive interactions; that the participation is at the same time restrained; and that questions of power relationships surface as an essential aspect to navigate. The intended empowering effect of the installation appears uncertain and requires further investigation.
\end{abstract}

Aesthetics. Assemblage. Audio. Engagement of participants. Performing archive. Sound recording.

\section{INTRODUCTION}

The Re-Volution $S$ ampler installation is a participatory, multi-layered assemblage of collective as well as individual performances of political songs. The installation is an experiment to reformat different archival models and practices that digital media and participatory practices offer. It aims to facilitate engaging experiences with archival sonic documents for contemporary audiences. The work contributes to the ongoing discourse on the performance of archives, mediatized recordings of liveness, and the challenges and opportunities working with participation and user engagement in the creation of continuously evolving archives.

Questions which appear to be relevant with regard to the engaging qualities of the work are, for instance, what are the aesthetics of participation and engagement in the Re-Volution Sampler? How does the installation engage a contemporary audience to participate in the historical sonic archive of political songs through singing and listening, and how does it connect the audience with the collectivities that the songs reflect? We have evaluated the installation at a semi-public location with qualitative and quantitative methods, and use a framework proposed by Fritsch et al. (2016) to discuss and reflect upon its engaging properties.
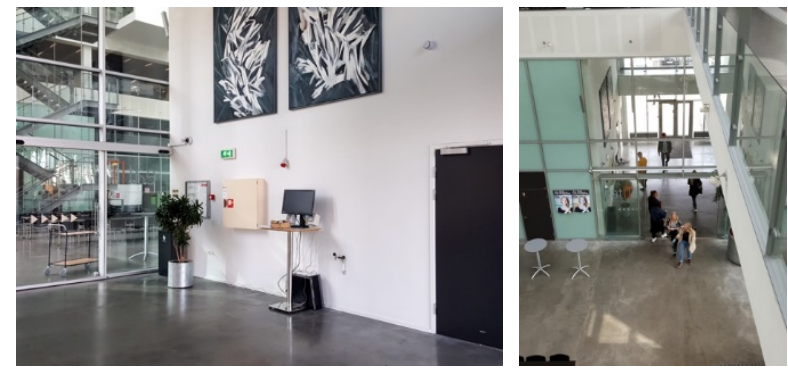

Figure 1: The installation at a semi-public location

This text describes related works, the Re-Volution Sampler installation (Figure 1), the conceptual framework for evaluation and the concrete evaluation set-up. The insights gained through the evaluation with regard to engagement are reported and discussed.

\section{RELATED WORKS}

The design of the Re-Volution Sampler installation is informed by experiences from our previous project Electromagnetic Lan dscape, made in collaboration with performance artist Ayaka Okutsu (Cermak-Sassenrath, Okutsu and Hasse, 2015). In the work, participants were invited to collectively play with the reception of live FM radio waves and create a cacophonous, participatory soundscape of transmissions. The Re-Volution $S$ ampler is also 
inspired by artworks such as Die G edanken sind frei by Susan Hiller (2012), and Ulysses Jukebox by Olof Olsson (2016), which can both be argued to work, in different ways, with the aesthetics of participation by inviting audiences to interact with sonic archives.

Die Gedanken sind frei is an installation with 100 political songs exhibited for 100 days at the dOCUMENTA 13 in Kassel. The songs are installed in a Wurlitzer walnut jukebox, and audiences can select different songs to be played, which originate from different political movements and eras. The lyrics of the songs are displayed on the walls surrounding the jukebox. A songbook accompanying the installation also presented the 100 songs. In its foreword, Hiller writes that "[s]ongs can get people talking and thinking" (2012, p. 3).

In Olsson's interactive installation Ulysses Jukebox, audiences can listen to a public reading marathon of James Joyce's work Ulysses (1920) by Danish writers, politicians and artists recorded at the Museum for Contemporary Art in Roskilde in 1998.

Both Hiller's and Olsson's installations use the jukebox as a presentation medium to invite audiences to become active, participating listeners by selecting and listening to songs or text read aloud. Similar to Die $G$ edanken $s$ ind frei and Ulysses Jukebox, the Re-Volution Sampler is also a jukebox inviting audiences to select and listen to sonic documents; however the Re-Volution Sampler further invites audiences to participate in creating the sonic archive by letting them listen as well as record their own singing of the songs on top of the existing recordings. In this way, the interaction facilitated between participants and sonic texts is also different from the interactions facilitated in Die Gedanken sind frei and Ulysses Jukebox.

\section{THE RE-VOLUTION SAMPLER INSTALLATION}

The Re-Volution $S$ ampler installation is an experiment in engagement with auditory texts. The installation integrates playback and recording of political songs (Figure 2). Participants not only consume the medium (to listen and receive) but (need to) create (add, extent or comment) it at the same time if it is not to vanish. For instance, participants can listen to a protest song (such as Merle Travis's Sixteen tons, or Eddy Grant's Gimme hope Jo'anna) and sing along, play an instrument, applaud, cheer or add verbal comments; and they can erase existing recordings and start new recordings. In this way the work facilitates a bottom-up structure, where the sonic material presented to the participants are also generated by the participants, as a case for appropriative participation. The participatory method is reflected in the installation content of protest songs which are arguably typically performed and appropriated. The installation aims not to normalize participants' experiences but to engage with a multiplicity of different yet collective notions of politics, history, identity, desire, and belief. Thus, the Sampler may become a collection, assemblage and testimony of the multiple personal and collective experiences of revolution people have and share across countries and cultures.
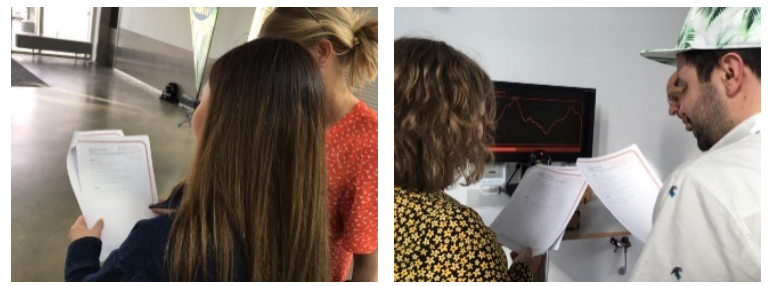

Figure 2: Participants inspect a title from the songbook (left); participants re-sample a song supported by one of the authors (right)

The installation consists of a high table, with a screen, desktop speakers, a microphone, a custom-made input controller with four directional buttons, and a stack of stapled songbooks (Figure 3 ). A desktop computer is located under the table parallel with the wall; mouse and keyboard are removed. When nobody interacts with the installation, it goes into attraction mode and the screen content changes every 48 seconds and randomly displays the available song titles. There is no sound from the installation in attraction mode. The songbooks (Figure 4) prompt participants to "Sing-along and record nine protest songs, or start your own song in an open slot!".

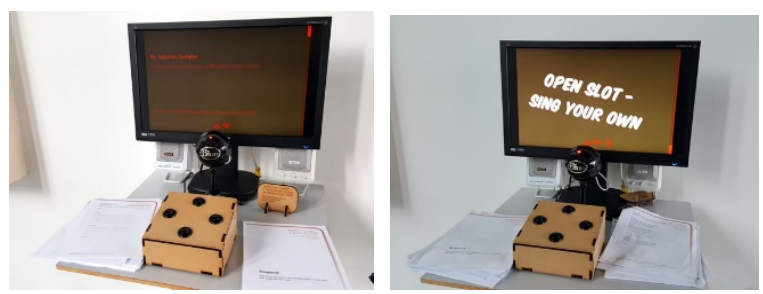

Figure 3: Setup on a high table; screen showing title (left) and the open slot (right)

The installation is set up in a semi-public space at a Danish university. The location is a short, wide corridor which connects one of the four ground floor entrances of the university with a large atrium. The corridor is separated from the atrium by an automatic sliding glass door. Opposite the installation is the university's cantine; the corridor is busy during the daily noon lunch hour (12 to $13 \mathrm{~h}$ ) with approximately 900 people entering and later leaving the cantine. 


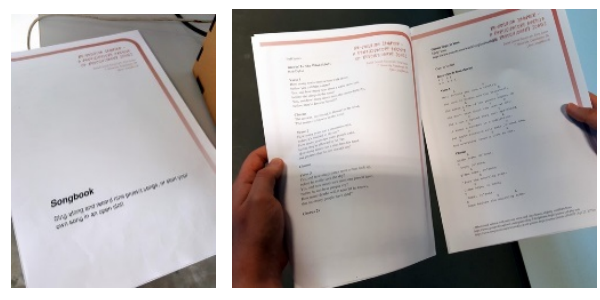

Figure 4: The songbook title page (left), and a double page from the songbook showing the complete lyrics of a song on the left (page back side) and the abbreviated 60 second version of a song on the right (front side; right)

The Re-Volution S ampler installation contains ten songs. Abbreviated 60 second versions of all songs were created by, for instance, removing verses and by changing the speed of songs slightly (Table 1 ). historical and geographical situatedness of the authors, both having a North European background. We recognize that there are many other songs that are not been part of the curated content of the installation, and therefore also included an "open slot" where participants are invited to contribute a song to the archive.

Participants can select one of nine slots which are labelled with song titles and are presented with information on the selected song (Figure 5, Figure 6 ), and are informed that they can proceed to listen to the song and resample it at the same time. The tenth slot is labelled "Open Slot", and participants are prompted to "Sing [their] own" (to initiate the process, the song Imagine is present at installation setup). Participants can choose to go back and

Table 1: Songs included in the installation (as ordered in the installation)

\begin{tabular}{|c|c|c|c|c|}
\hline Author(s)/performer(s) & Title & Year & Location & Abbreviated version \\
\hline Bob Dylan & Blowin' in the wind & 1967 & US & First verse and one chorus \\
\hline Eddy Grant & Gimme hope Jo'anna & 1988 & $Z A$ & First verse and one chorus \\
\hline Country Joe and the Fish & $\begin{array}{l}\text { I-feel-like-I'm-fixin'-to-die } \\
\text { rag }\end{array}$ & 1965 & US & $\begin{array}{l}\text { First two verses and two } \\
\text { chorus' }\end{array}$ \\
\hline $\begin{array}{l}\text { Jay Kogen, Jeff Martin and Wallace } \\
\text { Wolodarsky (words), Jeff Martin } \\
\text { (music)/Lisa Simpson }\end{array}$ & Union strike folk song & 1993 & US & Only one repetition \\
\hline $\begin{array}{l}\text { Tom Lundén/Det Internationale } \\
\text { Sigøjner Kompani }\end{array}$ & I kan ikke slå os ihjel & 1976 & $D K$ & First verse and one chorus \\
\hline Eva Lankov & $\varnothing$ jenbrynene & 1977 & $D K$ & First verse and one chorus \\
\hline Bots & Zeven dagen lang & 1976 & $N L$ & $\begin{array}{l}\text { First two verses and two } \\
\text { chorus' }\end{array}$ \\
\hline $\begin{array}{l}\text { Eugène Pottier (words), Pierre de } \\
\text { Geyter (music) }\end{array}$ & L'internationale & $\begin{array}{l}1871 \text { (words)/ } \\
1888 \text { (music) }\end{array}$ & $F R$ & First verse and one chorus \\
\hline Merle Travis/Tennessee Ernie Ford & Sixteen tons & $\begin{array}{l}1946 \text { (written)/ } \\
1955 \text { (recorded) }\end{array}$ & US & $\begin{array}{l}\text { First two verses and two } \\
\text { chorus' }\end{array}$ \\
\hline Open slot (John Lennon) & Imagine & 1971 & $G B$ & First verse \\
\hline
\end{tabular}

The songbooks contain these versions of the songs, with guitar chords (or tabs), as well as the complete lyrics. The songs curated for the $R e$ Volution $S$ ampler are commonly or popularly identified with a political cause, campaign or position. They are picked from numerous possible political songs; the selection should not be regarded as an attempt to make a canon of the most important or influential political songs. The selected content of predominantly songs popular in a Western context also reflects the cultural, select another slot, or start the resampling. The existing recording is played back, and at the same time, it is recorded together with any sonic input from the participants, and other (e.g. background) noise. After the sampling is complete, the participant is thanked and may continue interacting with the installation and, for instance, resample the same song again. The songs are resampled physically, that is, in real space, by using the speakers and the microphone, and each song is layered in a single file. 
The main objects of graphic design in the installation are the screen design (Figure 3, Figure 5 , Figure 6) and the design of the songbook (Figure 4) which both use a shared colour palette of black, white and red. Both use two fonts each, a sansserif font and a hand-written font. The sans-serif font on screen is used for technical information, such as instructions on the sampling. The slightly tilted hand-written font is used on-screen for songand artist-related information. The songbook uses the hand-written font only for the name of the installation in the top-right corner of each page, and the sans-serif font for everything else. The screen and the songbook also use a limited number of other graphical elements, that is, the screen features a red scroll bar on the right side of the screen to indicate the position of the currently selected screen among the ten song slots; the songbook features a red border around part of each page to signal the connection of the presented content to the installation. The screen uses a low resolution of only $320 \times 200$ pixels.
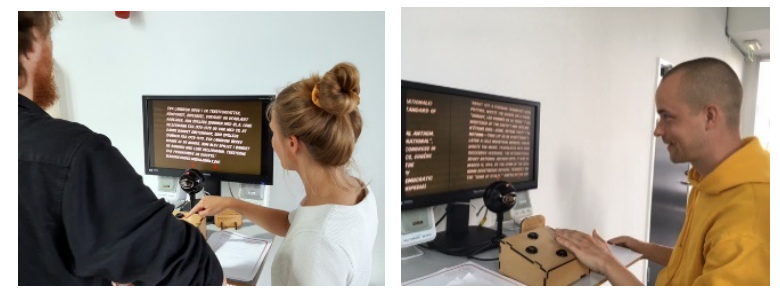

Figure 5: Participants briefly read the background information on a song before proceeding to the sampling

screen

The input controller is custom-designed and features four directional buttons for the participants to navigate the installation. The device is made from MDF, and is only clear-coated. A small wooden label giving the names of the installation and the authors is made the same way. Both take up and echo the rough home-made aesthetics of the screen and songbook design.

A real-time audio spectrum is displayed on screen during re-sampling based on the mix picked up by the microphone to give participants immediate, visual feedback and also indicate a too soft or too loud recording level.

\section{CONCEPTUAL FRAMEWORK}

Fritsch et al. (2016) propose a conceptual framework to discuss the aesthetic properties of what they term "media architecture". Their model builds upon Jaques Ranciere's notion of the distribution of the sensible as a concept and a tool for (1) the reflection and analysis of the design process, and (2) for studying the design in use. According to Fritsch et al. (2016, p. 1), Ranciere's notion of the distribution of $t$ he $s$ ensible can determine and differentiate modes of sense perception and modes of participation through different forms of engagement. This can effect the possible formation of communities and the experiences of what is shared and common: "The different forms of engagement are staged by the distribution of the sensible offered by the media architectural setup locally, but also govern the possibility to constitute a community on a more global scale." (Ibid., p. 3)

Fritsch et al. (ibid., p. 1) list four categories that enable specific articulation of the aesthetics of participation; (1) Modes of sense perception, (2) forms of engagement, (3) community, and (4) emancipation. Our focus is on the ways in which the installation can be argued to stage different forms of engagements - locally as well as in relation to the possibility of experiencing affinities to a community across history/geographies.

The modes of sense perception category (1) concerns the relations between the visual, auditory, and kinesthetic activations of sensory perception through the installation. Here, a question for discussion could be on the relations between the perceptual activations that the installation brings and the overall goal of the installation. The forms of engagement (2) addresses two aspects, that is, (a) the relation between active and passive participation - between being an operator, spectator or performer - and (b) the relation between the individual and the collective action. Here, a discussion could question which modes of sense perception determine the modes of participation. The experience of a community category (3) concerns the sensory and aesthetic constitution of the communities activated, and the intersection of resonating communities facilitated with the installation. The last category is the experience of emancipation (4) which concerns the relations between, for instance, viewer and actor, individual and community, user and designer, and is felt when there is a blurring of the opposition between e.g. "those who are individuals and those who are members of a community" (Ranciére, 2007, p. 279).

In relation to the categories we want to discuss which forms of participation are facilitated through the installation. Which (groups of) participants are heard? Which hierarchies does the installation create or challenge? What are the affinities or power relationships between designers and participants, or between participants and other participants, or between participants and technological frameworks?

While the Re-Volution $S$ ampler is not a media architectural project in a public space, but an installation in a semi-public place, we still think that Fritsch et al.'s framework are useful in order to discuss if/how media projects can reconfigure 
relations between individuals and communities. And similar to Fritsch et al.'s sound project Ekkomaten/Echoes from Møllevangen, the ReVolution Sampler is an interactive listening machine which engages audiences in sonic documents, making "it possible for people to experience different stories, feelings and atmospheres through their interaction with the machine" (ibid., p. 4).

\section{EVALUATION SET-UP}

The parameters of the set-up of the installation (such as timing and materiality) are selected to allow for anevaluation of the aesthetics of participation within the Fritsch et al. framework.

The duration of the installation was about seven days, from Wednesday evening until Wednesday evening. The duration was chosen to give everybody who frequents the location during the week the possibility to interact with the installation. A duration of one week also includes the various, quite different phases at this particular location: Lecture hours during weekdays, cantine rush hour weekdays at noon, tumultuous student Friday Bar, and quiet late afternoons, evenings and nights, and weekend.

The installation was set up to run for 24 hours a day. A specific schedule is followed to service the installation: The recordings are saved every night and the original condition restored for the first few days (up to and including Saturday). From Saturday until Tuesday the installation is left running without interfering with it. On Tuesday afternoon was an interview session for which the installation was reset again. In addition to saving recordings and restoring the installation to working order, the services also offered the opportunity to check any intervention with the installation, e.g. tinkering with the speaker settings and the removal of songbooks.

The high table makes it easy for participants to walk up to the installation and start interacting. The absence of chairs might also signal that participation only takes a short time. There is a decent amount of space around the installation location for participants not to feel cramped in, and the small size of the table top invites groups of people to gather around it, and to sing with e ach other ${ }^{1}$, and not (only) for or towards the installation (Figure 2). The initial supply of ten songbooks is intended to signal abundant availability, and participants should feel that they can take them home without compromising the use of the installation by other people.Participants engage with the installation in the (overlapping and

\footnotetext{
1 No headphones are provided for individual engagement.
}

transient) roles of listener (or spectator), singer (actor/performer) or co-curator of the open slot (operators). We focus on how participants actively participate and not on participants that e.g. stand and observe others interacting. Participants were self-selected among the university students and staff (during the whole installation period), and recruited among interested colleagues (for three special testing periods, which took between one and three hours each).

\section{RESULTS}

We did three interview sessions with five participants we met on location as well as with six invited participants. The interviews were conducted as semi-structured interviews and took between ten and 40 minutes. All interviews were audio recorded and circa-transcribed (Bundgaard, Mogensen and Rubow, 2018).

There were 44 recordings of all the ten different songs in the seven sessions, including guided sessions in which the authors were present. There were 34 recordings in sessions when the authors were not present. Of these recordings, 16 feature singing or other song-specific audio input such as rythmic screams or whistling; 16 feature no singing but some interaction such as button presses, changing the speaker volume, installation-related discussion, or test noises (such as "hello"); and two feature no interaction at all.

The song selection meant that the content was not specifically tuned to accommodate students in their early twenties. Several participating students told us in interviews that the installation missed modern songs. Even a colleague, who is probably around 55 years old, pointed out that we had been picking "old songs". The majority of participants, young and old, claimed to know only one song, Blowin' in the wind. Among the participating Danes, nearly all knew one of the Danish songs included (I kan ikke slå os ihjel), but all interviewees we asked claimed not know the other (Øjenbrynene).

In sessions 1 and 2 there was only one instance of singing; all other instances of singing were in sessions 3, 4 and 6; specifically, in session 3 (which included the Friday evening and night) there was lots of singing. Familiarity with the installation, having seen or used it before, and the relaxed atmospheres of the Friday Bar and the weekend certainly seemed to have prompted participation.

It was not technically recorded how many resamplings happened for each song. The original recording was audible in 28 out of 34 recordings, vaguely audible in two, and fully inaudible in four. In cases the original recording of a song is audible or vaguely audible, a low number of re-samplings (fewer than six) is assumed. When the original 
recording was fully inaudible it is assumed that it was re-sampled more than five times. The most resampled slot was Øjenbrynene with five recordings, followed by five other slots with four recordings each (Blowin', Gimme hop e, l-feel-like-l'm-fixin'-todie rag, I kan ikke slå os ihjel, open slot). The least popular slots were Sixteen tons with two recordings and The Internationale with one recording.

We believe the location of the installation qualifies as a semi-public space, and was sufficiently suited to the experiment. The location was visible from within the cantine during operation hours (weekdays 7.45 to $18 \mathrm{~h}$ ), and from the sides, i.e. through the sliding glass door and also through the outside door. As one participant noted, the location is a "very visible spot", at least "during lunch hour". While the noise from the cantine during lunch hour is often considerable, the location is most of the time pretty quiet, except for the outside door being opened and the indoor door opening automatically. Outside the cantine rush hour there is usually probably only a handful of people present on the ground floor of the building.

\section{DISCUSSION}

To discuss the installation, we adopt Fritsch's et al.'s (2016) conceptual framework and four categories that enable to articulate specific aesthetic properties.

Both of the authors were prominently involved in some aspects of evaluating the installation (Figure 2). Kwastek (2013, p. 93) notes that the author(s) of a work not only "create(s) the interaction proposition by designing, programming, or implementing the underlying system, by constructing, selecting, or assembling its digital assets and material components, and often also by selecting or configuring the required setting", but can also "be present in other roles, for example as recipient, observer, mediator or fellow player". In case of the Re-volution Sampler, we have acted as both authors and as observers of how participants used and experienced the work, as mediators explaining the work to participants, and occasionally, as fellow players, singing along with participants. The roles we have taken, can be argued to be necessary in order to evaluate the work, but can also be seen as problematic. For example, it can be argued that interviewees who know they talk to us as the creators of a work, hold back criticism. Also, the selection of songs and the recordings made during the three interview sessions (on Tuesday, Friday and Thursday) in the presence of the authors are likely unrepresentative of participant behaviours or contributions.

\subsection{Modes of sense perception}

The materials used and the design employed in the installation were intended to facilitate a slightly rough, accesssible and authentic experience to resonate with the installation's topic. The screen, songbook and controller maintain a home-made, improvised, amateur and raw look and feel. For instance, they share the classic protest colour red in an one-colour newsprint palette, fonts, as well as arrangement and orientation of text. The screen has a low resolution, and the controller shows it is made from a cheap, industrially mass-produced material through a transparent finish. The songs are supplied in stapled paper songbooks. A computer, keyboard and mouse were not present or (prominently) visible.

The interviewed participants expressed various positions with regard to how the sensory experience of the installation reflected its aim, that is, to engage contemporary audiences in political songs. Some participants thought that the connection between the sensory dimension and the conceptual aspect of the installation was obvious: "It is a pixilated aesthetics, it is not the aesthetics of an mp3 player, but older, like an LP - the 60/70s crunchy crisp needle aesthetics. The visual and the sound align so well and with the revolution theme of the past. [...] It fits with L'internationale which has its own leftist aesthetics, whereas songs from now would demand another aesthetics. The visual dimension mirrors the time - what L'internationale is to me." ${ }^{2}$

One participant commented on the retro visual style of the installation: "I like it - it fits with the selection of old-fashioned revolutionary songs. Everything is retro. If there was a modern song I would criticize it [...] Conceptually from the artistic side it is obvious that it is the people's song, so it is obvious to resample it in some sense." One participant similarly reports a "documentary" look and feel: "I like the aesthetics of it. I like this documentary kindof edgy look, very nice."

Another participant experienced that the installation had a clear political connotation: "The archive consists of historical and generally acknowledged or defined protest songs - in this way the archive in the installation does spur debate as to whether it consists of protest songs". Another participant also emphasized the political aspect of the installation: "I recognized the first title, Blowin' in the Wind, as a protest song and thought that the installation probably was political in one way or another. And that seems to fit very well as the installation, as I see it, is metapolitical and is about how we sing about politics.". One participant did not recognize the political context of the songs and suggested to

\footnotetext{
${ }^{2}$ Some participants' quotes are translated from Danish.
} 
include Hit the road Jack (US 1960) in Ray Charles' later hit version which is not a protest song to our knowledge.

Other participants felt that the notion of singing on top of other people's layered recordings mimicked and mediated the political song experience: "The experience of singing on top of other people's singing is how I think a protest song sounds. Typically, more than thousand people sing together, so this is how it sound - with voices not sounding as clear and clean as on a polished pop song." However, the fact that the voices in the layered recording become more and more muddy was addressed as a problem by a different participant: "One thing that is proper is that the articulations in the song is clear so it helps other people in a revolutionary context. [...] I would not be able to sing the song without the help of others and that is a revolutionary idea that we organize together."

Other participants did not feel as if they were united by singing together with other people on the sampled audio track, but mainly felt that it was comforting and less awkward than to sing alone in public: "To sing on top of other people's singing feels more comforting. It is difficult songs to sing and we don't feel like that we are great singers [...], and we can become very self-focused when singing, but we let go of this focus as we could not hear our own voice that clearly in the mix, so it wasn't so awkward."

\subsection{Forms of engagement}

The selection of songs is, clearly, a significant curatorial issue. Showing or exhibiting something usually means, showing oneself (Schlögel 2018, p. 39). We picked political songs that from our experience, background and estimate are classic political titles (and excluded radical, right-wing, fascist, terrorist and violent titles). The curated song selection was intended to accommodate a wide range of participants with songs from different eras and music styles, which address a variety of topics. It was to inspire and facilitate interaction, not to dominate or to limit it. We are aware, and it has been confirmed in the interviews, that the selection was not specifically tuned to the taste of Danish or international students in their early twenties. Participants expressed that they experienced a feeling of disconnect with many of the songs. "I do not put myself back to the youth revolution in sixtyeight with Bob Dylans song, because it is not something that I really know anything about." Most of the participants agreed that the songs in the archive were outdated: "The songs you have chosen to be part of the installation archive are all connected to revolutions that have been done. These are songs my mom would sing. They are of the past." Some participants explicitly questioned the selection of songs and one of them asked us to "think about what revolutionary history [you] curate from".

Interestingly, the song that nobody claimed to know (Øjenbrynene), was selected most often for recording, while the song that appears most popular in the interviews (Blowin' in $t$ he $w$ ind) ranges only on the second place. This might indicate that Øjenbrynene was selected for curiosity, while Blowin' was selected for familarity. This is reflected in the number of recordings and renditions: There are four recordings for Blowin', with two of them with singing; and there are five recordings for Øjenbrynene, but only one rendition with singing. Curiosity is also likely the reason the open slot received much attention (and then also singing).

Common behavior was (sometimes hectic or almost violent) button presses right at the start of the re-sampling, presumably to stop it. Many recordings have only been re-sampled (or listened to) once or twice; the original recording is still well audible. The recording of test noises appears to be popular, presumably to verify that the installation is indeed recording, or possibly to substitute for singing. There was an approximate halfway split between recordings with no discernable contribution of participants (this often goes together with them abandoning the recording in mid-air), and recordings with (often enthusiastic) singing of participants.

When we enquired in the interviews which songs we should include in the installation when we show it again, the participants made very few suggestions of political songs from the last 20 years; prominent among them was Beyonce's Formation (US 2016), Green Day's American idiot (US 2004) and Tupac's Changes (US 1998). Other suggested songs included The Beatles' Revolution (GB 1968), The Men They Couldn't Hang' Ghosts of $C$ able Street (GB 1986) and other punk rock songs, Miriam Makeba's Pata pata (ZA/US 1967), Pink Floyd's Another brick in the wall (GB 1979), and Nena's 99 Luftballons (DE 1983/4).

\subsection{Experience of community}

Many participants did not directly feel an aesthetic constitution of a community facilitated through the installation: "It is more an experience of participating in an art installation than an experience of resonating with a community." Other participants did also not feel like singing together with a community of people: "In the installation we do not get the feeling of singing together with other people, because we cannot see them [...] It might as well be a [karaoke machine]. If there had been videos of people singing, it would have been great, then we could see more and more people singing on the screen." However some of the participants 
did feel that other communities were brought into resonance through the installation: "I was looking at the words, as it was in another language (French) I did therefore not look at the screen until the end of the song, but then I saw a waveform and felt the presence of people who have sung before me here." The participant established an aesthetic connection with three groups of people who are involved in singing a particular song (L'internationale). He identifies the people present on location at the time, the "people who have sung here before me", and "those people who have ever sung the L'internationale together". He noted that "those are the three audiences I sang with. [...] I felt part of all three singing communities".

The observations of and experiences with the installation with regard to the creation of a community appear to point out a mismatch between installation topic and location context. The community present at the installation location and the situation at a university seem to clash with the community established or maintained by political songs. This mismatch is only briefly mitigated (or maybe suppressed) by the Friday Bar which is an anomaly for a university context. Another observation that might point out that the community for the kind of activity as prompted by the installation is not present at the location, is that no participant asked for a specific song to be included for hi s/her s ake, but in all cases the formulation was something like "young people probably know this one or that one" or "another song popular with some people might be ...". This appears to indicate that participants were aware that there was a community for singing political songs and potentially engaging in political acts, and they might (or might not) be part of it, but to some of participants the community was not present at this location.

\subsection{Experience of emancipation}

Many participants interacted with the installation over the course of the installation period. Participant behavior might have included subversive acts such as erasing a recording of a song they disagreed with, or the removal of the song from the songbook; or even more explicit behaviors such as vandalizing the installation. Nothing of this sort happened (Figure 6). Judging from the recordings, most participants, if they interacted, played (or s ang) a long. No radical songs were recorded in the open slot; no (e.g. spoken) political messages recorded; and no pages were ripped from songbooks. Songbooks were folded and crumbled, and staples gave way, but only one of the ten songbooks went missing. Recordings were blank, we speculate, because participants listened to them repeatedly without singing, iteratively erasing the recordings until they were silent, and not purposefully erased because of political disagreement. Speaker settings were presumably changed to mitigate trying sonic conditions, for instance, during the Friday Bar, and not to cause feedback on purpose. There was one case of sonic appropriation. A group of participants replaced a song with a one not promoted in installation (or contained in the songbook); in the slot of Blowin' in the wind, they recorded a single rendition of Oh happy day (US 1967/1969).

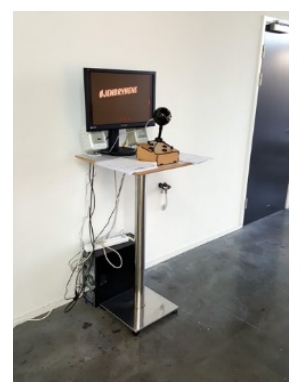

Figure 6: Somebody placed the microphone on top of the controller

The participants were playing by the rules, and their restraint engagement with the political content might indicate an insecurity or uninterest to express political convictions through singing protest songs in a semi-public space, in front of friends, fellow students or colleagues. Speech acts of controversial, minority or marginal views were not expressed in the protest song recordings, and only rarely in the interviews.

In terms of the experience of emancipation, it seemed as if the installation created a feeling of empowerment for some of the participants (from the generation of the authors): "I felt awkward singing, but the space was open and now that I have done it once, I feel like I could do it again. It gives the feeling helly eah, I can sing L'internationale, so I feel a little empowered." Other participants felt that they became aware of the political aspect of the song, after having interacted with the installation: "I haven't paid attention to the lyrics before. I know the song [Gimme hope], but I didn't know that it was about apartheid. I could only remember a sentence here and there - but it is only when you see the whole thing written down that you become aware.".

To most of the participants however, their participation in the installation mostly created some sort of reflection or debate among themselves, thinking about the oppositions between listener and singer and co-curator of the political songs, between them and others or other communities. Some participants reflected upon their experience of interacting with the Re-Volution Sampler and discussed if there are any revolutionary songs connected to issues of today such as climate change: "Are there no songs about climate change? This should really be the case ." Other 
participants wondered: "It is interesting to think about what decades the songs [in the archive] are made. What are e.g. the revolutionary songs from the 1990s? When we were super capitalist - is there something[from that period]? [...] Are there any decades where there are no revolutionary songs? That nobody would know it on a global scale?". ${ }^{3}$

\section{CONCLUSION}

The Re-Volutionary Sampler seeks to collapse the archival modus operandi of storage and dissemination, of, in this case, political songs from the last decades, with the presence and interactivity of singing and listening participants into an ever-evolving archive. The installation invites participants to listen to political songs and simultaneously to perform vocal collectivities, stretching beyond and across time and space, to arguably create and constantly re-create itself as a participatory performing archive.

We have discussed audience reactions and experiences collected through observations, interviews, and some quantitative measures from an installation of the Re-Volution $S$ ampler in a semi-public space, in relation to the conceptual framework of aesthetics of participation as formulated by Fritsch et al. (2016). We observed many participants to actively and productively engage with the installation. At the same time, the participation appeared restrained. One reason we identify is the mismatch of communities present at the installation location. We found that most participants agreed that sensory experiences of the installation (1) reflected the aim of the installation as being a protest song archive and succeeded to engage contemporary audiences with political songs. Questions of power relationships surfaced in form of the curated song selection as essential aspect of the work. Many participants questioned the engaging qualities of the song selection with protest songs of an earlier date, which they felt unconnected to. Interacting with the installation (2) required some skills not all participants had or were willing to employ in the installation context. That is, participants had to know (some of) the songs, and command basic skills to contribute, for instance, to sing, while there might exist social conventions that stand against participation (such as the avoidance of singing in public). Emancipation (3) might be too large or broad of a concept to describe participants' experiences with the installation; however, some participants felt empowered by singing together with others, and for some participants the interaction with the installation was an opportunity

\footnotetext{
${ }^{3}$ In many areas of the world, political songs apparently never went out of fashion; for instance, in Kashmir (Musch-Borowska 2019).
}

to reflect upon the question if there are any revolutionary songs connected to communities dealing with political issues of today. The empowering effect of the installation appears uncertain; one aspect is the missing expression of marginal or controversial positions, for instance, in the form of recordings of alternative political visions. Some of the participants felt that they were brought into resonance with other communities (4) through the installation.

Future work includes to investigate the installation's empowering and emancipating aspects in detail. Two variables to work with can be the curated content of the installation and the installation location.

\section{REFERENCES}

Borggreen, G. and Gade, R. (eds.) (2013) Performing Archives/Archives of Performance. Museum Tusculanum Pr., Copenhagen.

Bundgaard, $H_{\text {., }}$ Overgaard Mogensen, $H$. and Rubow, C. (eds.) (2018) Antropologiske Projekter: En Grundbog. Samfundslitteratur, Copenhagen.

Cermak-Sassenrath, D., Okutsu, A. and Hasse, S. (2015) Electromagnetic Landscape - In-between signal, noise and environment. ISEA 2015: Disruption Proceedings. isea2015.org/ proceeding/submissions/ISEA2015_submission_ 307.pdf (retrieved September 14, 2019).

Dourish, P. (2004) What we talk about when we talk about context. Personal Ubiquitous Comput., 8 (1), pp. 19-30.

Fritsch, J., Grönvall, E., and Breinbjerg, M. (2016) Analyzing the aesthetics of participation of media architecture. MAB Proceedings of the 3rd Conference on Media Architecture Biennale, article no. 4.

Hiller, S. (2012) Song Book. Mousse, Milan.

Huybrechts, L., Schepers, S., and Dreessen, K. (2014) Participation and Risky Trade-offs. In Huybrechts, L. (ed.), Participation Is Risky: Approaches to Joint Creative Processes. Valiz, Amsterdam, pp. 9-79.

Jenkins, H., Puroshotma, R., Clinton, K., Weigel, M. and Robison, A. J. (2005) Confronting the challenges of participatory culture: Media education for the 21st century. www.newmedialiteracies.org/wpcontent/uploads/pdfs/NMLWhitePaper.pdf (retrieved February 1, 2018).

Musch-Borowska, B. (2019) Patriotismus-Pop zur politischen Lage. Tagesschau.de, August 26. www.tagesschau.de/ausland/kaschmir-165.html (retrieved August 26, 2019). 
Schäfer, M. T. (2008) Bastard Culture: User Participation and the Extension of Cultural Industries. PhD diss. Utrecht Univ., Utrecht. dspace.library.uu.nl/handle/1874/33564 (retrieved September 14, 2019)
Schlögel, K. (2018) Das sowjetische Jahrhundert. Archäologie einer untergegangenen Welt. 3rd ed. Beck, Munich.

Kwastek, K. (2013) Aesthetics of Interaction in Digital Art. MIT Pr., Cambridge. 